young electricians into two groups, students and graduates. The students of approved colleges and apprentices and assistants in engineering works can become 'students'. When a student has passed certain qualifying examinations and has attained the age of twenty-one years, he can be elected a graduate. A graduate, however, is not a 'chartered electrical engineer'. This status can only be attained after his training and experience exceeds seven years, two of which must have been in a position of superior responsibility in the profession. He has to send in an election form signed by five members and giving a complete account of his training and experience, which is scrutinised by an election committee. $\mathrm{He}$ must also be twenty-six years of age. When he fulfils all these somewhat onerous conditions, he is elected an associate of the Institution, and can call himself a chartered electrical engineer.

It will be noticed that there is a discontinuity in the training of an electrical engineer, namely, the gap between the university or technical college and works. Most students have no connexion with engineering and so have to make their own arrangements with manufacturing firms. Naturally, they want to go to the best-known firms, but it generally happens that these firms have already all the student apprentices they want. Hence they have to try to get into works about which they know nothing.

This has led to the adoption by a few colleges of the 'sandwich' system of training. The best-known of these colleges is Faraday House, London, which was founded more than forty years ago and now has about four hundred students. The course lasts for four years. The first year is a purely collegiate course in general engineering. During the second year the student is apprenticed under supervision to a mechanical engineering works either in Great Britain or abroad, the college making all the arrangements for him. The college is affiliated with 170 works and railways in Great Britain and abroad, for teaching purposes. Advanced theoretical training is given in college during the third year, and for the final year the students go to electrical manufacturing works and power stations throughout the country and to railways, and communication companies, etc. Those who have passed successfully through the course, several of whom also take the London B.Sc. (Engineering), receive the diploma which enables them to become graduates of the Institution of Electrical Engineers without further examination. The advantage of the system is that the student is under the same supervision throughout his course.

The recent extension of research laboratories in connexion with works has led to a limited demand for men who have done post graduate research work in university laboratories. These men usually write theses which help them to get the higher degrees of M.Sc., Ph.D. and D.Sc. Research laboratories also take young graduates whom they train specially in their own methods of research so as to qualify them for posts on their staff.

A.R.

\title{
Solid Solutions and Liquid Mixtures
}

\section{$\mathrm{T}$} $\mathrm{E}$ discussion arranged in Section $\mathrm{B}$ (Chemistry) on Sept. 6 at the York meeting of the British Association, was finally divided into two parts as it was agreed that the differences between solid solutions and liquid mixtures were too great for the subjects to be covered usefully in a single discussion. Prof. C. H. Desch in his paper on re-arrangements in the solid state referred to the importance of solid solu. tions in metallurgy and said that systems in which a series of solid solutions, stable at high temperatures, resolves itself into two or more phases on cooling are of frequent occurrence. Such systems are of two types. In the first, and most usual, the change takes the form of the separation of a new phase from solution in the same manner as the crystallisation of a salt from water. A solubility curve can be drawn and eutectoid structures similar to the eutectics produced from liquid solutions are produced. Familiar examples are the iron-carbon and ironnickel systems, and analysis of the constituents shows that a definite migration of nickel has taken place in the solid phase. In the second type of re-arrangement which has been observed in recent years, a solid solution homogeneous at high temperatures and having the solute atoms statistically distributed throughout its lattice assumes a new arrangement on cooling through a certain point, the solute atoms taking up regular positions and so forming a super-lattice. The change is reversed on heating. A typical example is furnished by the gold-copper alloys. The equilibrium is attained very quickly and the change can be followed by electrical resistance tests. Magnesium-cadmium alloys give a similar series and the changes are at present largely unexplained although the number of such systems may be considerable.
The discussion on mixed liquids was opened by Prof. Irvine Masson who indicated that its scope is limited to mixtures of non-electrolytic fluids. The main chemical interest in such liquids lies in the formation of inter-molecular compounds but Prof. Masson pointed out that before deviations of liquid mixtures from an ideal mixture law can be interpreted as evidence of chemical interaction or compound formation, the effects of the other possible causes of combination betwoen either similar or dissimilar molecules must be disentangled, namely, the van der Waals' cohesion forces and electrical coupling between polar molecules. In each of these alternatives as in chemical combination we have also to contemplate the reverse process of dissociation. In actual fact van der Waals' cohesion is present in every mixture of any two liquids. Electrical coupling between polar molecules occurs in all mixtures except the 'normal' liquids. Thus where chemical combination occurs it is invariably accompanied and complicated by the other two forces.

Discussing the criteria for a normal liquid Prof. Masson pointed out the danger of assuming that those liquids are normal which when mixed together give straight line property-composition curves. The use of the Ramsay-Eotvos rule concerning surface energies, Trouton's rule concerning latent heats, and Debye's polar moments, leads to the characterisation of a normal liquid as one the molecules of which remain sufficiently independent to attract one another by no forces other than the van der Waals' cohesion which they show in the vapour state. A normal liquid thus has the characteristics of a non-polar but imperfect gas. For properties such as specific volume, viscosity, vapour pressure and heats of mixing, all of which are strongly influenced by cohesion and give 
indirect measurement, fundamentally, of intermolecular cohesion, the simple mixture law does not hold. We are dealing with two opposing actions, the influence of the cohesion of each kind of molecule with others of its own kind being attenuated by the dilution, while on the other hand the attenuation is counteracted, more or less, by the mutual cohesion set up between the two kinds of component molecules. We cannot state precisely what the normal behaviour of mixtures of two non-polar substances would be but the deviations from the straight line due to cohesion reach their maximum, for a given pair of components, at a composition not far from equimolecular.

With regard to electrical coupling between polar molecules, after referring to the view which attributed the van der Waals' forces to transient polarisation of non-polar forces Prof. Masson pointed out that as before the magnitude of the deviation depends on two opposed influences. In addition while the end-toend coupling of polar molecules gives a complex of larger electric moment, in the side-by-side coupling the two individual polarities tend to neutralise each other, and accordingly caution is required in interpreting data for electric moments. Quantitative interpretation of the cohesions displayed by polar molecules is very difficult and Prof. Masson considers that Langmuir's presentation of the mutual cohesions of compound molecules as additive functions of their chemical constituents is inadequate. Evidence based purely on deviations from the mixture-law which might be accounted for by the relatively strong deviations due to mutual dipole cohesion is accordingly insufficient to establish the formation of chemical compounds, short of the isolation of a solid compound with distinctive properties.

Prof. G. Kendall in his paper on compound formation in liquid mixtures classified compounds existing in liquid mixtures in two types, addition compounds and substitution compounds. In the former, of which acetic acid-aniline forms an example, there is a definite increase in molecular complexity and a wide deviation in physical properties from the mean of the components. In the second type, of which phenol-cresol is an example, there is no increase in molecular complexity and the physical property. composition curves are more nearly linear. Formation of compounds of the first type depends mainly on the diversity in electrochemical character of the radicals of the components, the extent of compound formation increasing with such diversity. The reverse holds with compounds of the second type, similarity in the radicals being the dominant factor, part of the associated molecule being replaced by essentially equivalent groups. The results of a detailed examination of the two ternary systems ethyl acetate-water-alcohol and ether-water-alcohol were discussed in relation to these generalisations.

Discussing dipole association in liquid mixtures Dr. N. V. Sidgwick pointed out that in contrast to non-associated substances, associated substances give a molecular polarisation curve which rises to a maximum and then falls with increasing concentration; with non-associated substances the molecular association decreases from infinite dilution as the concentration increases. The dipole association may be due to an orientation of the molecules by the dipole forces, or to their polymerisation, and molecular weight determinations and determinations of the molecular polarisation enable the degree of association, $x$, to be calculated on the assumption that non-polar double molecules are formed. Thus the values of $x$ obtained for nitrobenzene, which has a molecular polarisation five times as great at infinite dilution as in the pure liquid, by electrical and cryoscopic methods in benzene agree roughly up to about $2 N$. solutions $(0.46$ by polarisation, 0.57 by cryoscopy). The mass-action association constant rises considerably from $0 \cdot 26$ at $0 \cdot 1 N$. to $0 \cdot 39$ and 0.77 at $2 N$. showing that the association is not due to a definite polymerisation but to an orientation of the polar molecules which diminishes their activity. The values of $x$ obtained for nitrobenzene in different solvents, decrease with the dielectric constant of the solvent as is shown in the table below :

$\begin{array}{lcc}\text { Solvent. } & \text { Dielectric constant, } & x \text { at } 1 N \text {. } \\ \text { Carbon disulphide } & 2 \cdot 63 & 0.353 \\ \text { Benzene } & 2 \cdot 29 & 0.313 \\ \text { Carbon tetrachloride } & 2.24 & 0.284 \\ \text { Cyclohexane } & 1.88 & 0.269\end{array}$

\section{Oceanographic Instruments*}

$\mathrm{T}$ HE most complete survey of the physical oceanography of an ocean was carried out by the German research vessel Meteor in the South Atlantic. The plan of the expedition centred largely upon discovering the general movement of the water masses, the circulation theory of Bjerknes having provided an additional means of attacking this problem. This necessitates exact data of the distribution of density of the water throughout the ocean, as do all hydrographic calculations. These values of density are obtained by calculation from the temperature and chloride content of the water at various depths and the greatest attainable accuracy is sought, since the final picture rests on very small differences. The years 1925-27 were spent by the Meteor in collecting such data at more

- Deutsche Atlantische Expedition auf dem Forschungs-und Vermessungsschiff Meteor, 1925-1927. Wissenschaftliche Ergebnisse, herausgegeben im Auftrage der Notgemeinschaft der Deutschen Wissenschaft von Prof. Dr. Albert Defant. Band 4, Teil 1: Ozeano graphlsche Methoden und Instrumente. Von Dr. Georg Wüst, Dr. Tafeln. (Berín und Leipzig: Walter de Gruyter und Co., 1832).

than three hundred positions down to depths often exceeding three miles. Gear and instruments must stand up to their work under severe conditions, so it says much for their efficiency that the original plans were fully carried out.

The results of the expedition are now being published. Part I of vol. 4, "Ozeanographische Mothoden und Instrumente" by Wüst, Böhnecke and Meyer, gives a very full account extending over 300 pages with numerous illustrations of the instrumentsthermometers, water bottles, winch and current meters. A final chapter is devoted to the technique and organisation of chloride titrations carried out on board.

Two types of deep-sea reversing thermometers were used, one with an outer casing protecting it from the effect of pressure, the other not so protected. The latter acts as both thermometer and mano. meter. It was found in calibrating to have a constant pressure coefficient and was used to calculate the actual depths at which water samples and tempera-

No. 3284, Vol. 130] 